$€ 7148$ ) and \$9200, respectively, and the cost per additional quality adjusted life year (QALY) was \$44000 and $\$ 27200$. The authors concluded that these costs were similar to those of a number of existing medical interventions. However, their lay responder model used costs from a police responder pilot. It is likely that the cost per QALY of a public access scheme will be much higher, owing to the large number of defibrillators needed to provide adequate coverage. Unlike automated external defibrillators used by a police service, public access defibrillators are fixed to a location, and the location of future arrests cannot be predicted precisely from the location of previous arrests.

\section{Conclusions}

Targeted placement of defibrillators in public places such as airports and shopping centres, frequented by a large number of susceptible people, could, at best, increase overall survival from $5.0 \%$ to $6.3 \%$. Further expansion of the coverage of public access defibrillators to enable lay use in all potentially suitable sites would require much greater resources and would pro- duce little additional improvement in survival. Public access defibrillators should not be provided in preference to the expansion of defibrillation given by first responders or increased cardiopulmonary resuscitation by bystanders.

Contributors: See bmj.com

Funding: British Heart Foundation.

Competing interests: None declared.

1 Sedgwick ML, Dalziel K, Watson J, Carrington DJ, Cobbe SM. The causative rhythm in out-of-hospital cardiac arrests witnessed by the emergency medical services in the Heartstart Scotland Project. Resuscitation 1994;27:55-9.

2 Wilcox-Gok VL. Survival from out-of-hospital cardiac arrest. Med Care 1991:29:104-14.

3 Secretary of State for Health. Saving lives: our healthier nation. London: Department of Health, 1999

4 Cummins RO, Chamberlain DA, Abramson NS, Allan M, Baskiett PJ, Becker $\mathrm{L}$, et al. Recommended guidelines for uniform reporting of data from out-of-hospital cardiac arrest: the Utstein Style. A statement for health professionals from a task force of the American Heart Association, the European Resuscitation Counci, the Heart and Stroke Foundation of the European Resuscitation Council, he Heart and Stroke Foundation of Canada, and

5 Nichol G, Hallstrom AP, Ornato JP, Riegel B, Stiell IG, Valenzuela T, et al Potential cost-effectiveness of public access defibrillation in the United States. Circulation 1998;97:1315-20.

(Accepted 2 April 2002)

\title{
Angiotensin converting enzyme insertion or deletion polymorphism and coronary restenosis: meta-analysis of 16 studies
}

\author{
François Bonnici, Bernard Keavney, Rory Collins, John Danesh
}

\begin{abstract}
Objective To assess the association between genotype at the insertion or deletion polymorphism of the angiotensin converting enzyme gene and risk of coronary restenosis after percutaneous coronary intervention.

Design Meta-analysis of studies before July 2001 that reported on these genotypes and risk of coronary restenosis after a percutaneous coronary intervention, with or without coronary stenting.

Results 16 studies, involving 4631 patients undergoing a percutaneous coronary intervention, yielded 1683 patients with restenosis after a mean weighted follow up of 5.5 months. The combined odds ratio for restenosis in people with the DD genotype was 1.23 (99\% confidence interval 1.03 to 1.46). When studies were grouped by size, however, the combined odds ratios for restenosis in people with the DD genotype were 1.94 (1.39 to 2.71) for studies with less than 100 cases, 1.33 (0.92 to 1.93 ) for studies with $100-200$ cases, and 0.92 (0.72 to 1.18 ) for studies with more than 200 cases (trend $\mathrm{P}=0.02$ ). Similarly, when studies were grouped by genotyping procedures, significantly larger odds ratios were found in the studies that did not conceal disease status from laboratory staff and in the studies that did not use a second polymerase chain reaction amplification to reduce genetic mistyping.
\end{abstract}

Conclusion Compared with other studies, larger and more rigorous studies show a weaker association between the angiotensin converting enzyme gene DD genotype and restenosis. Publication bias or detection biases can produce artefactual associations at least as large as those that might be expected for common polymorphisms in complex diseases, suggesting the need for larger and more rigorous genetic epidemiological investigations than are now customary.

\section{Introduction}

Restenosis after a percutaneous coronary intervention is one of the principal limitations of this technique, occurring in up to $50 \%$ of patients undergoing the procedure without stenting and in about $20 \%$ of patients receiving stents. ${ }^{1}$ Despite a lack of good evidence that susceptibility to restenosis is genetically determined, several studies have investigated polymorphisms that might be associated with restenosis. As the angiotensin converting enzyme insertion or deletion (I/D) polymorphism is strongly associated with plasma and cellular angiotensin converting enzyme concentrations, it has been considered a strong candidate. ${ }^{2}$ It has been suggested that the incidence of coronary restenosis after a percutaneous coronary intervention is much higher in patients with the angiotensin converting enzyme DD genotype (which is associated with particularly high plasma angiotensin converting enzyme levels) than in others, but published 
observational studies are conflicting. ${ }^{3-18}$ To help clarify the evidence we considered all available relevant studies in a meta-analysis.

\section{Methods}

We sought studies published before July 2001 of the angiotensin converting enzyme insertion or deletion polymorphism and coronary restenosis after a percutaneous coronary intervention, with or without coronary stenting, by computer based searches (Medline, Embase, PubMed, Web of Science), reviews of reference lists, hand searching relevant journals, and correspondence with authors. For the electronic searches we used combinations of key words relating to the angiotensin converting enzyme gene (for example, angiotensin converting enzyme, ACE, polymorphism, insertion/deletion, I/D, $\mathrm{D} / \mathrm{I}$ ) and to restenosis (for example, coronary, restenosis, percutaneous, angioplasty, PTCA, stent, stenting). We included all identified studies. Articles in languages other than English were translated.

From each study we abstracted (supplemented by correspondence with investigators) geographical location, race of participants, numbers of cases and controls, the coronary intervention procedure, definition of restenosis, frequency of insertion or deletion genotypes, genotyping methods and laboratory procedures, mean age, and duration of follow up.

We estimated odds ratios by comparing cases who developed coronary restenosis after a percutaneous coronary intervention with controls who did not within the same study. We did this under the prior hypothesis that individuals who were homozygous for the angiotensin converting enzyme D allele were predisposed to restenosis compared with those with the ID or II genotypes. ${ }^{19}$

\section{Results}

We identified 16 relevant studies concerning a percutaneous coronary intervention, 11 without stenting

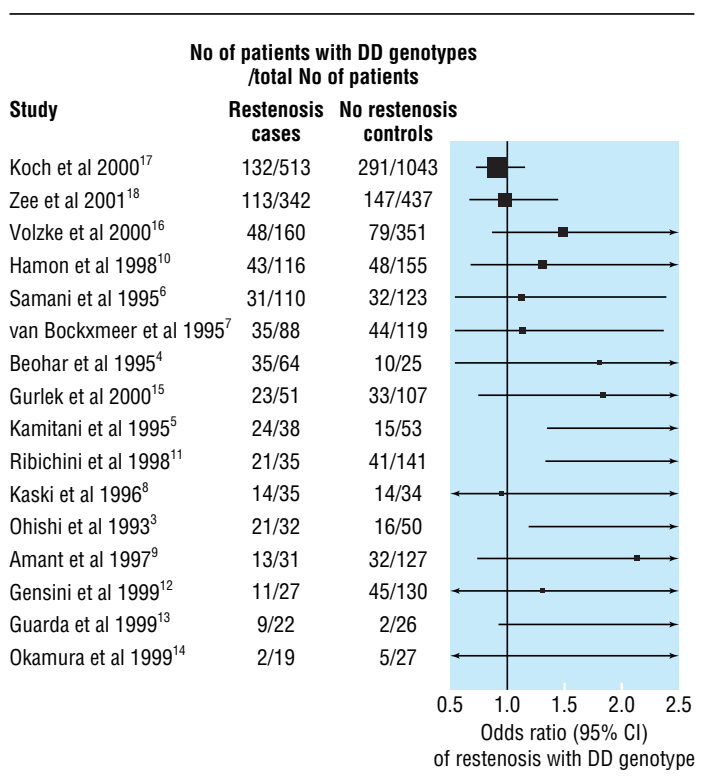

Fig 1 Meta-analysis of 16 published studies of angiotensin converting enzyme insertion or deletion polymorphism and coronary restenosis

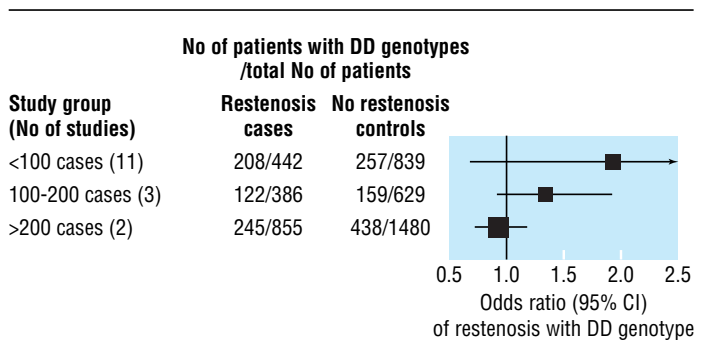

Fig 2 Meta-analysis of published studies of angiotensin converting enzyme insertion or deletion polymorphism and coronary restenosis grouped by size

(2535 patients) and five with stenting (2096 patients), yielding 4631 patients (94\% white) undergoing such interventions. ${ }^{3-18}$ All the studies used quantitative computer assisted methods to define restenosis as a narrowing of the coronary diameter by $50 \%$ or more at follow up compared with the minimal luminal diameter immediately after intervention. Overall, 1683 of these patients (mean age 60 years) developed coronary restenosis after a mean weighted follow up of 5.5 months. The studies were conducted in Australia, Chile, France, Germany, Italy, Japan, Spain, Turkey, the United Kingdom, and the United States. ${ }^{3-18}$ Following correspondence with the authors, it was confirmed that genotyping had been performed by staff unaware of the disease status of the patients in four of the five studies with more than 100 cases,${ }^{6}{ }^{16-18}$ compared with only two of the 11 studies with less than 100 cases. $^{48}$

Overall, the combined odds ratio for restenosis in people with the DD genotype was 1.23 (99\% confidence interval 1.03 to 1.46 ; test for heterogeneity $\chi^{2}=24.1$, $\mathrm{df}=15, \mathrm{P}=0.06$ : fig 1 ). We found no significant heterogeneity between studies of percutaneous coronary intervention with stenting and those without stenting (combined odds ratios for the DD genotype of $1.17 v 1.27$ respectively; $\chi^{2}=0.23, \mathrm{df}=1, \mathrm{P}=0.6$ ). When studies were grouped by size, however, the combined odds ratios for restenosis were 1.94 (1.39 to 2.71) for the 11 studies with less than 100 cases, $^{3-5}{ }^{7-9}{ }^{11-15} 1.33$ (0.92 to 1.93) for the three studies with $100-200$ cases, ${ }^{6}{ }^{10}{ }^{16}$ and 0.92 (0.72 to 1.18) for the two studies with more than 200 cases (fig 2). ${ }^{17}{ }^{18} \mathrm{~A}$ test for trend across these three groups of studies was significant $\left(\chi^{2}=5.6, \mathrm{df}=1, \mathrm{P}=0.02\right)$. Similar results were observed when odds ratios for restenosis were calculated per $\mathrm{D}$ allele in these three groups (1.74 v $1.00 v 0.98$, respectively). When studies were grouped by genotyping procedures, significantly larger odds ratios were observed in the studies that did not conceal disease status from laboratory staff (combined odds ratios for the DD genotype of $1.87 v 1.02$ respectively, $\chi^{2}=9.7, \mathrm{df}=1$, $\mathrm{P}=0.002)^{35} \quad 7^{9-15}$ and in the studies that did not use a second polymerase chain reaction amplification to reduce mistyping of angiotensin converting enzyme ID heterozygotes as DD (1.55 $v 1.13$, respectively; $\chi^{2}=4.05$, $\mathrm{df}=1, \mathrm{P}=0.03){ }^{3}{ }^{5-7} 1012-14$

\section{Discussion}

Weaker associations between the angiotensin converting enzyme DD genotype and restenosis were found in larger and more rigorous studies than in other studies. We had observed a similar trend in published studies of 


\section{What is already known on this topic}

Restenosis after a percutaneous coronary intervention is one of the principal limitations of the technique

Genotype at the angiotensin converting enzyme insertion or deletion polymorphism is proposed to be important in restenosis

\section{What this study adds}

Weaker associations between the angiotensin converting enzyme DD genotype and restenosis were found in larger and more rigorous studies than in other studies

Publication bias or detection biases, or both, can produce artefactual associations at least as large as those that might be expected for common polymorphisms in complex diseases

the angiotensin converting enzyme DD genotype and myocardial infarction. ${ }^{19}$ These findings have important implications for genetic epidemiology, suggesting that publication bias or detection biases can produce artefactual associations at least as large as those that might be realistically expected for common polymorphisms in complex diseases.

We thank the investigators for supplying additional information and Alison Palmer for plotting the figures. RC holds a British Heart Foundation personal chair. JD holds the Raymond and Beverly Sackler Research Award in the Medical Sciences.

Contributors: All authors contributed to the design, analysis, and interpretation of the study. FB and JD will act as guarantors for the paper.

Funding: FB was supported by a Rhodes scholarship.

Competing interests: None declared.

1 Serruys PW, de Jaegere P, Kiemeneij F, Macaya C, Rutsch W, Heyndrickx $\mathrm{G}$, et al. A comparison of balloon-expandable-stent implantation with balloon angioplasty in patients with coronary artery disease. Benestent balloon angioplasty in patients with coronary

2 Tiret L, Rigat B, Visvikis S, Breda C, Corvol P, Cambien F, et al. Evidence, from combined segregation and linkage analysis, that a variant of the angiotensin I-converting enzyme (ACE) gene controls plasma ACE levels. Am J Hum Genet 1992;51:197-205.

3 Ohishi M, Fujii K, Minamino T, Higaki J, Kamitani A, Rakugi H, et al. A potent genetic risk factor for restenosis [letter]. Nat Genet 1993;5:324-5.
4 Beohar N, Damaraju S, Prather A, Yu QT, Raizner A, Kleiman NS, et al. Angiotensin-I converting enzyme genotype DD is a risk factor for coronary artery disease. J Investig Med 1995;43:275-80.

5 Kamitani A, Rakugi H, Higaki J, Ohishi M, Shi SJ, Takami S, et al. Enhanced predictability of myocardial infarction in Japanese by combined genotype analysis. Hypertension 1995;25:950-3.

6 Samani NJ, Martin DS, Brack M, Cullen J, Chauhan A, Lodwick D, et al Insertion/deletion polymorphism in the angiotensin-converting enzyme gene and risk of restenosis after coronary angioplasty. Lance 1995;345:1013-6.

7 Van Bockxmeer FM, Mamotte CD, Gibbons FA, Burke V, Taylor RR. Angiotensin-converting enzyme and apolipoprotein $\mathrm{E}$ genotypes and restenosis after coronary angioplasty. Circulation 1995;92:2066-71.

8 Kaski JC, Zhang Y, Calvino R, Vasquez-Rodriquez JM, Castro-Beiras A, Jeffrey S, et al. Angiotensin-converting enzyme insertion/deletion polymorphism and restenosis after coronary angioplasty in unstable angina pectoris. Am J Cardiol 1996;77:875-7.

9 Amant C, Bauters C, Bodart JC, Lablanche JM, Grollier G, Damchin N, et al. D allele of the angiotensin I-converting enzyme is a major risk factor for restenosis after coronary stenting [see comments]. Circulation 1997:96:56-60.

10 Hamon M, Amant C, Bauters C, Richard F, Helbecque N, Passard F, et al Dual determination of angiotensin-converting enzyme and angiotensin-II type 1 receptor genotypes as predictors of restenosis after coronary angioplasty. Am J Cardiol 1998;81:79-81.

11 Ribichini F, Steffenino G, Dellavalle A, Colajanni E, Camilla T, Vado A, et al. Plasma activity and insertion/deletion polymorphism of angiotensin I-converting enzyme: a major risk factor and a marker of risk for coronary stent restenosis. Circulation 1998:97:147-54.

12 Gensini F, Battaglini B, Fatini C, Guazzelli R, Falai M, Chioccioli M, et al. Polimorfismo I/D del gene ACE e A1166C del gene AT1R quali fattori di rischio di restenosi dopo angioplastica coronarica. Minerva Cardioangio 1999;47:516

13 Guarda E, Fajuri A, Marchant E, Martinez A, Jalil J, Illanes G, et al. D/D genotype of the gene for angiotensin converting enzyme as a risk factor for post-stent coronary restenosis [see comments]. Rev Esp Cardio 1999;52:475-80.

14 Okamura A, Ohishi M, Rakugi H, Katsuya T, Yanagitani Y, Takiuchi S, et al. Pharmacogenetic analysis of the effect of angiotensin-converting enzyme inhibitor on restenosis after percutaneous transluminal coronary angioplasty. Angiology 1999;50:811-22.

15 Gürlek A, Güleç S, Karabulut H, Bokesoy I, Tuter E, Pornir G, et al. Relation between the insertion/deletion polymorphism of the angiotensin converting enzyme gene and restenosis after coronary stenting. J Cardiovascular Risk 2000;7:403-7.

16 Völzke H, Hertwig S, Rettig R, Motz W. The angiotensinogen gene 235T variant is associated with an increased risk of restenosis after percutaneous transluminal coronary angioplasty. Clin Sci 2000;99:19-25.

17 Koch W, Kastrati A, Mehilli J, Bottiger C, van Beckerlath N, Schornig A Insertion/Deletion polymorphism of the angiotensin I-converting enzyme gene is not associated with restenosis after coronary stent placement. Circulation 2000;102:197-202.

18 Zee RYL, Fernandez-Ortiz A, Macaya C, Pintor E, Lindpaintner K, Fernandez-Cruz A. ACE D/I polymorphism and incidence of post-PTCA restenosis: a prospective, angiography-based evaluation. Hypertension 2001;37:851-5.

19 Keavney B, McKenzie C, Parish S, Palmer A, Clark S, Youngman L, et al for the International Studies of Infarct Survival (ISIS) Collaborators. Large-scale test of hypothesised associations between the angiotensinconverting-enzyme insertion/deletion polymorphism and myocardial infarction in about 5000 cases and 6000 controls. Lancet 2000;355:434-42.

(Accepted 17 April 2002)
Two main interventions are available for opening up blocked coronary arteries: balloon angioplasty and open heart surgery. In percutaneous coronary angioplasty a wide lumen catheter is fed from the groin up to the aortic root and into the coronary arteries. A guide wire is passed through the catheter and across the stenosis in the coronary artery. The wire is used to guide a balloon (with a stent mounted on it if necessary) into the diseased section of the artery. The balloon is inflated, pushing the atheroma outwards and enlarging the lumen of the artery. A stent can be expanded to fit the artery. Once the stent is in place (confirmed by angiography), the wires and the catheter are removed.

Arterial restenosis remains a serious problem after percutaneous coronary angioplasty. It tends to occur within three months of the procedure and is due to proliferation of smooth muscle as a reaction to vessel injury. Restenosis used to occur in over $30 \%$ of patients after percutaneous coronary angioplasty, but with the use of stents and advances in stent design and improved techniques for implanting them the rates now lie between $10 \%$ and $20 \%{ }^{1{ }^{2}}$ This is comparable to the $10 \%$ of vein grafts that are lost in the year after bypass grafting. The main risk factors for restenosis after percutaneous coronary angioplasty are diabetes, thrombus formation or inflammation in the coronary tree, and small vessel size.

Two recent trials found no difference between percutaneous coronary angioplasty plus stenting and bypass surgery for death or myocardial infarct in

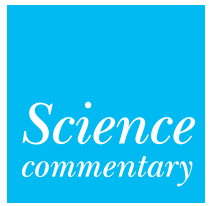

Waller Department of Cardiology, St Mary's Hospital, London W2 1NY Iqbal Malik specialist registrar Abi Berger science editor, $B M J$ 